\title{
Formação de professores de ciências exatas numa perspectiva inclusiva
}

\author{
Training of science teachers in an inclusive perspective
}

\author{
Josiane Pereira Torres (jtfisica@gmail.com) \\ Universidade Federal de São Carlos (UFSCar); Grupo de Pesquisa Formação de Recursos Humanos em \\ Educação Especial - FOREESP \\ Enicéia Gonçalves Mendes (eniceia.mendes@gmail.com) \\ Universidade Federal de São Carlos (UFSCar); Grupo de Pesquisa Formação de Recursos Humanos em \\ Educação Especial - FOREESP
}

\section{Resumo:}

Esse artigo teve como objetivo apresentar uma investigação em busca da presença/ausência ou insuficiência de saberes acerca da Educação Especial em currículos de cursos de licenciaturas em ciências exatas de instituições públicas de um estado brasileiro. Foi utilizada uma abordagem do tipo documental, na qual Projetos Políticos Pedagógicos e Matrizes Curriculares foram analisados. Foram extraídos excertos nos quais inferências explícitas ou implícitas referentes à Educação Especial e/ou à Educação Inclusiva faziam-se presentes nesses documentos. E, ainda, foi realizada uma análise das tendências das disciplinas apresentadas nas matrizes curriculares. De maneira geral, notou-se que a temática ainda é pouco explorada nos currículos das licenciaturas analisados e quando ocorre, em muitas vezes, é insuficiente.

Palavras-chave: Educação Especial; Formação de Professores; Ciências exatas.

\begin{abstract}
:
This paper aimed to show a research focused on the search for presence/absence or insufficiency of knowledge about special education in undergraduate curricula in exact sciences of public institutions of a Brazilian state. By means of documentary study, were analyzed Political Pedagogical Projects and Curricular Matrices. Fragments of text that contained inferences about Special Education and/or Inclusive Education were extracted and are discussed in this paper. An analysis of the trends of the disciplines presented in the curriculum matrices was also carried out. In general, it should be noted that this topic is still little explored in undergraduate curricula analyzed and when it occurs, in many cases it is insufficient.
\end{abstract}

Key-words: Special Education; Teacher training; Exact Sciences.

\section{INTRODUÇÃO}


Oferecer condições que garantam o acesso e o sucesso escolar de estudantes do Público-Alvo da Educação Especial ${ }^{1}$ (PAEE) tem sido um desafio da atualidade, uma vez que a escola encontra-se despreparada para lidar com as especificidades desses estudantes, sendo organizada, em sua maioria, para um público homogêneo de alunos. Desse modo, o alunado que se distancia da "normalidade" pode enfrentar grandes dificuldades para permanecer na escola. Entre os obstáculos da escola, destacamos a precária ou a insuficiente formação docente para atuar com tais estudantes, considerando que pesquisas apontam que até mesmo os professores especializados para lidarem com estudantes PAEE sentem-se despreparados para trabalhar com as diferentes deficiências (MENDES; CIA; CABRAL, 2015). Logo, seria de se esperar que os professores da educação básica também enfrentassem essa sensação, inclusive os das ciências exatas.

Eventos internacionais contribuíram significativamente com o caminhar de políticas nacionais centradas na educação de estudantes com necessidades educacionais especiais. Dentre eles, pode-se apontar a Conferência Mundial sobre Educação para Todos (UNESCO, 1990), em Jomtien, na Tailândia, ocorrida no ano de 1990, a qual marcou um momento de mudanças políticas em diversos governos presentes em prol de oferecer uma "educação para todos". O documento resultante do evento destacou a precariedade da educação básica e apontou os caminhos para um avanço rumo a uma educação de qualidade. Um desses caminhos recai sobre a formação docente, uma vez que uma má formação de professores pode ser uma grande barreira para a efetiva inclusão de estudantes PAEE no ensino regular (GLAT, 2000), conforme discutimos anteriormente. Nesse ponto, é destacado o notável papel do professor, assim como dos demais profissionais da educação, sendo tais profissionais considerados de fundamental importância para implementação de uma educação de qualidade.

Do ponto de vista da educação, em uma perspectiva inclusiva, pesquisas têm apontado que, atualmente, "as licenciaturas não estão preparadas para desempenhar a função de formar professores que saibam lidar com a heterogeneidade posta pela inclusão" (PLETSCH, 2009, p. 150). E,

\footnotetext{
1 São estudantes do Público-Alvo da Educação Especial os estudantes com deficiência, transtornos globais do desenvolvimento e altas habilidades/superdotação (BRASIL, 2008).
} 
Não se trata de responsabilizar pessoalmente os professores pela insuficiência das aprendizagens dos alunos, mas de considerar que muitas evidências vêm revelando que a formação de que dispõem não tem sido suficiente para garantir o desenvolvimento das capacidades imprescindíveis para que crianças e jovens não só conquistem sucesso escolar, mas, principalmente, capacidade pessoal que lhes permita plena participação social num mundo cada vez mais exigente sob todos os aspectos (BRASIL, 1999, p. 26).

Não são recentes os apontamentos em documentos oficiais com relação à preocupação da formação docente em uma perspectiva inclusiva. Nossa constituição já direcionava a necessidade da formação docente capacitada para contribuir com um sistema educacional que inclua a todos verdadeiramente (BRASIL, 1988). E, além de incluir todos, é importante que ofereça uma educação de qualidade destinada a todos os estudantes, sem distinções e com "igualdade de condições para o acesso e permanência na escola" (BRASIL, 1988).

No âmbito internacional, a Declaração de Salamanca reforçou o compromisso com a Educação para Todos (1990), apresentando suportes e recomendações para uma educação de qualidade para estudantes PAEE e reportando, entre esses suportes, a preocupação com a formação de professores. Todo um capítulo é destinado a reforçar uma adequada formação docente como fator chave para a construção de escolas inclusivas (UNESCO, 1994). Ressalta-se a atenção para uma formação na qual todos os professores estejam preparados para exercerem sua autonomia em sala de aula, de modo que apliquem suas habilidades na adaptação do currículo a fim de possibilitarem meios para que todos os estudantes, inclusive o PAEE, tenham acesso (UNESCO, 1994). Assim, entende-se que cabe ao professor de uma determinada licenciatura aliar suas habilidades próprias de sua formação para discernir como pode se dar a adaptação dos conteúdos curriculares de modo a contribuir para um acesso globalizado. Nesse ponto, o documento deixa margem para a possibilidade do trabalho em cooperação entre professores e pais e, ainda, a colaboração entre professores e profissionais especialistas. Vale pontuar a recomendação de que os cursos de formação de professores deveriam prever uma formação pautada no preparo para lidar com especificidades dos alunos, na qual "as habilidades requeridas para responder as necessidades educacionais especiais deveriam ser levadas em consideração durante a avaliação dos estudos e da graduação de professores" (UNESCO, 1994, s/p). 
Dois anos depois, a Lei de Diretrizes e Bases da Educação Nacional (LDB) (BRASIL, 1996) veio definir os docentes como profissionais da educação sendo aqueles "professores habilitados em nível médio ou superior para a docência na educação infantil e nos ensinos fundamental e médio" (BRASIL, 1996, p. 24). A LDB também estabeleceu a garantia de professores capacitados para atenderem as especificidades dos estudantes PAEE, isto é, "professores com especialização adequada em nível médio ou superior, para atendimento especializado, bem como professores do ensino regular capacitados para a integração desses educandos nas classes comuns" (BRASIL, 1996, p. 23).

A proposta de diretrizes para a formação inicial de professores da educação básica, em cursos de nível superior (BRASIL, 2000), também revela que entre as exigências do papel do professor encontra-se "assumir e saber lidar com a diversidade existente entre os alunos" (p. 4).

As Diretrizes Curriculares Nacionais para a Formação de Professores da Educação Básica, em nível superior, curso de licenciatura, de graduação plena (BRASIL, 2002) expõe declaradamente a questão da formação docente e a educação inclusiva.

\begin{abstract}
A educação básica deve ser inclusiva, no sentido de atender a uma política de integração dos alunos com necessidades educacionais especiais nas classes comuns dos sistemas de ensino. Isso exige que a formação dos professores das diferentes etapas da educação básica inclua conhecimentos relativos à educação desses alunos (BRASIL, 2002, p. 25 e 26).
\end{abstract}

E, em seu artigo $6^{\circ}$, ao elencar o que se considerar na construção do projeto pedagógico dos cursos de formação de professores, o documento mencionou que há de se considerar "conhecimentos sobre crianças, adolescentes, jovens e adultos, aí incluídas as especificidades dos alunos com necessidades educacionais especiais e as das comunidades indígenas" (BRASIL, 2002, p. 3).

No decreto $n^{\circ}$ 8.752, de 2016, que dispõe sobre a Política Nacional de Formação dos Profissionais da Educação Básica, documento previsto no Plano Nacional de Educação (PNE) aprovado pela Lei no 13.005, de 24 de junho de 2014, no capítulo 1, apresenta-se os princípios postos para a formação dos profissionais $^{2}$ da educação,

\footnotetext{
${ }^{2}$ Profissionais da educação compreende: professores, pedagogos e funcionários da educação atuantes nas redes públicas e privadas da educação básica ou a elas destinados.
} 
destacando-se dois aspectos que indicam um possível indício de uma preocupação com uma sociedade inclusiva e com a redução de desigualdades sociais e educacionais.

O primeiro ponto sinaliza, como princípio para a formação de profissionais da educação, "o compromisso com um projeto social, político e ético que contribua para a consolidação de uma nação soberana, democrática, justa, inclusiva e que promova a emancipação dos indivíduos e dos grupos sociais" (BRASIL, 2016, s/p, grifo nosso). Nesse trecho, o ato de tornar a nação inclusiva é mencionado como princípio a ser considerado para a formação de professores e, embora não fique explícito a quem se destina a palavra inclusiva, pode-se considerar que é atribuída aos grupos excluídos das esferas sociais, incluindo, desse modo, a população de pessoas com deficiência.

A questão das desigualdades educacionais e sociais é abordada no segundo princípio: “o compromisso dos profissionais e das instituições com o aprendizado dos estudantes na idade certa, como forma de redução das desigualdades educacionais e sociais" (BRASIL, 2016, s/p). Nesse ponto, embora novamente sem explicitar, sabe-se que os estudantes do Público-Alvo da Educação Especial enfrentam dificuldades em acompanhar o currículo escolar da educação básica, levando-os a defasagens educacionais em comparação com os demais estudantes.

Ao apresentar os objetivos do referido documento em seu art. 3, novamente notase uma preocupação em formar profissionais da educação comprometidos com a construção de um ambiente educativo inclusivo.

VI - promover a formação de profissionais comprometidos com os valores de democracia, com a defesa dos direitos humanos, com a ética, com o respeito ao meio ambiente e com relações étnico-raciais baseadas no respeito mútuo, com vistas à construção de ambiente educativo inclusivo e cooperativo (BRASIL, 2016, s/p, grifo nosso).

Uma formação comprometida com os valores da democracia e dos direitos humanos, conforme é descrito no referido objetivo, leva a uma compreensão de que essa formação deve beneficiar a todos os educandos, independentemente de raças, etnias, deficiências etc. 
Explicitamente, a Educação Especial é citada nesse documento, em seu art. 12, em uma das iniciativas para se considerar na previsão de programas e ações integrados e complementares do Planejamento Estratégico Nacional.

VI - estímulo ao desenvolvimento de projetos pedagógicos que visem a promover desenhos curriculares próprios à formação de profissionais do magistério para atendimento da Educação Profissional e Tecnológica, Educação de Jovens e Adultos, Educação Especial, Educação do Campo, de povos indígenas e de comunidades remanescentes de quilombos (BRASIL, 2016, s/p).

Embora haja respaldo em documentos oficiais para a presença da temática da Educação Especial nos currículos de cursos de formação de professores, ainda se nota que essa não é uma realidade de muitos cursos no país. No tópico a seguir buscou-se especificamente analisar essa temática na regulamentação de cursos de professores das áreas de ciências exatas.

\subsection{Educação Especial e as licenciaturas de ciências exatas}

Analisando as diretrizes curriculares para os cursos de Física (BRASIL, 2001a), Química (BRASIL, 2001b) e Matemática (BRASIL, 2001c) notou-se consenso entre os documentos no que diz respeito à formação de um profissional com sólidos conhecimentos específicos, bem como com um adequado preparo para lidar com os conhecimentos pedagógicos nas situações profissionais durante atuação na educação básica.

As Diretrizes para os cursos de Matemática (BRASIL, 2001c) diferenciam-se ao prever a formação de um profissional com características que o capacite para uma

visão de que o conhecimento matemático pode e deve ser acessível a todos, e consciência de seu papel na superação dos preconceitos, traduzidos pela angústia, inércia ou rejeição, que muitas vezes ainda estão presentes no ensino-aprendizagem da disciplina (BRASIL, 2001c, p. 3, grifo nosso).

Embora não seja uma manifestação declarada de que essa previsão de conhecimento acessível para todos direcione-se aos estudantes PAEE, pode-se inferir que esse público esteja incluído como todos, sem distinção.

Sucessivamente ao perfil almejado, as diretrizes sinalizam as competências e habilidades previstas para a formação desses profissionais. Notou-se indícios de uma 
formação que capacite para o trabalho em colaboração quando mencionada a "capacidade de trabalhar em equipes multi-disciplinares" (BRASIL, 2001c, p. 3). Nesse ponto, pode-se destacar esse como sendo um perfil muito importante, visto as possibilidades que o trabalho em equipe/colaboração pode contribuir com o bom andamento do processo de ensino aprendizagem.

Notou-se, ainda, entre as diretrizes, a possibilidade de relacionar o conhecimento específico de formação com outras áreas do conhecimento, conforme explicitou-se nas diretrizes de Matemática: "estabelecer relações entre a Matemática e outras áreas do conhecimento" (BRASIL, 2001c, p. 4) e nas da Física "reconhecer as relações do desenvolvimento da Física com outras áreas do saber” (BRASIL, 2001a, p. 4). Sobre currículos constituídos por conhecimentos que se inter-relacionam, Theobald (2006) defende que

as orientações pedagógicas atuais necessitam dar sua resposta concreta na
identidade dos cursos de licenciatura em Matemática e Física garantindo a
possibilidade da aplicação dos diferentes saberes em interface com outros
campos de saber que resultam da expansão das aplicações da Matemática e
da Física nas décadas mais recentes pois, ao mesmo tempo, que se prevê a
formação de um profissional específico que domina um conjunto de saberes
específicos, deve vislumbrar sua flexibilidade tão necessária
contemporaneamente (THEOBALD, 2006, p. 6).

Nessa perspectiva, uma formação docente em ciências exatas que potencialize a correlação entre os conhecimentos específicos com os conhecimentos da Educação Especial deveria prever, em sua estrutura curricular, por exemplo, disciplinas que instrumentalizassem para a prática do ensino de Física, Química ou Matemática com os estudantes PAEE, ao contrário da oferta de disciplinas específicas da Educação Especial, às vezes presentes nos currículos, mas totalmente dissociadas dos demais conhecimentos.

De modo geral, pode-se dizer que os documentos mencionados não conferem um caráter inclusivo, de forma explícita, fato já enunciado anteriormente (BASSO, 2015). No entanto, embora as referências que foram destacadas não se dirijam especificamente aos estudantes PAEE, essas dão margem à interpretação que podem remeter, inclusive, a eles. E, considerando que esses documentos, entre outros, são importantes para a constituição de currículos de cursos de ciências exatas, pode-se esperar que essa 
temática (Educação Inclusiva) pode não ser considerada relevante nas grades curriculares, fato que pode resultar em grande prejuízo já que se considera relevante

incluir na agenda dos cursos de formação de professores, e demais licenciaturas, a discussão sobre como articular os conhecimentos, os fundamentos e práticas de educação inclusiva na grade curricular e no projeto pedagógico dos cursos do ensino superior (BRUNO, 2007, p. 6).

A análise das diretrizes dos cursos não indicou com clareza se e como esse tipo de conteúdo tem sido abordado no contexto dos cursos de licenciaturas na área de ciências exatas. Dessa forma, uma análise como a delineada nesse estudo possibilitou investigar com maior proximidade a efetividade, ou não, das recomendações propostas nas diretrizes.

\section{PERCURSO METODOLÓGICO}

Essa pesquisa tratou-se de uma investigação qualitativa, sendo que a coleta e análise de dados se deram por meio documental, cuja amostra e fonte de investigação foram os Projetos Políticos Pedagógicos (PPP) e Matrizes Curriculares (MC) de cursos presenciais de Licenciaturas em Ciências Exatas de instituições públicas de um estado brasileiro.

O motivo dessa análise ter como fonte de dados os PPP e MC dos cursos baseiase no fato de que são esses documentos que governam a formação que será recebida pelos licenciandos. Compreende-se os PPP como o projeto daquilo que se pretende alcançar. Logo, se pretende-se alcançar uma formação docente com o mínimo de preparo para a educação inclusiva, é nesse documento que se materializará tal ideal. Conforme pontua Mesquita e Soares (2009), a análise desses tipos de documentos

nos permite traçar um perfil do profissional formado na instituição ao se inquirir, a partir do documento, sobre quais saberes ele, o profissional, deve dominar e qual postura epistemológica trabalhada na sua formação (MESQUITA; SOARES, 2009, p. 123).

Inicialmente, foi realizado o levantamento das instituições públicas que ofertavam os cursos de licenciaturas em ciências exatas (Física, Química e Matemática), oferecidos na modalidade presencial, compreendendo um total de 36 licenciaturas. Nesse estudo, optou-se por não caracterizar e identificar as instituições de ensino 
superior participantes. Assim, os cursos analisados encontram-se identificados por códigos definidos, conforme segue no Quadro 1.

Quadro 1 - Relação das universidades analisadas

\begin{tabular}{|l|l|}
\hline \multicolumn{1}{|c|}{ Universidades } & \multicolumn{1}{|c|}{ Licenciaturas e respectivos códigos de identificação } \\
\hline Universidade Estadual 1 - Campus 1 & Física (LF1), Química (LQ1), Matemática (LM1) \\
\hline Universidade Estadual 1 - Campus 2 & Física (LF2), Matemática (LM2) \\
\hline Universidade Estadual 1 - Campus 3 & Física (LF3), Matemática (LM3) \\
\hline Universidade Estadual 1 - Campus 4 & Física (LF4), Química (LQ2), Matemática (LM4) \\
\hline Universidade Estadual 1 - Campus 5 & Física (LF5), Matemática (LM5) \\
\hline Universidade Estadual 1 - Campus 6 & Física (LF6), Química (LQ3), Matemática (LM6) \\
\hline Universidade Estadual 2 - Campus 1 & Ciências exatas (LCE1), Matemática (LM7) \\
\hline Universidade Estadual 2 - Campus 2 & Física (LF7), Química (LQ4), Matemática (LM8), \\
\hline Universidade Estadual 2 - Campus 3 & Química (LQ5) \\
\hline Universidade Federal 1 - Campus 1 & $\begin{array}{l}\text { Física integral (LF8), Física noturno (LF9), Química } \\
\text { (LQ7), Matemática (LM9) }\end{array}$ \\
\hline Universidade Federal 1 - Campus 2 & Física (LF10), Química (LQ6) \\
\hline Universidade Federal 1 - Campus 3 & Física (LF11), Química (LQ8), Matemática (LM10) \\
\hline Universidade Federal 2 & Física (LF12), Química (LQ9), Matemática (LM11) \\
\hline Universidade Estadual 3 & $\begin{array}{l}\text { Física (LF13), Integrada em Química e Física (LQF), } \\
\text { Matemática (LM12) }\end{array}$ \\
\hline
\end{tabular}

Fonte: Elaboração própria.

Conforme os dados apresentados no Quadro 1, cinco instituições de ensino superior (Federais e Estaduais) e seus respectivos campi estiveram envolvidas no estudo. Após o levantamento das instituições e dos cursos oferecidos, as páginas da internet de cada curso foram consultadas individualmente para a coleta dos PPP e MC dos cursos. Dois planos não se encontravam disponíveis na internet, dessa forma foi feito contato com a secretaria do curso via e-mail solicitando o envio do documento, no entanto, não houve retorno. Considerando que os documentos foram adquiridos por meio de sites da internet e esses podem ser alterados, é importante ressaltar que os acessos e downloads dos arquivos ocorreram entre os meses de maio e junho do ano de 2017.

De posse dos arquivos, cada documento foi cuidadosamente analisado em busca da presença ou ausência de tópicos que apontassem indícios direto ou indireto das temáticas referente à Educação Especial e/ou à Educação Inclusiva. Embora os PPP tenham sido lidos na íntegra, as inferências foram buscadas nas sessões de objetivos do curso; Disciplinas e Competências e Habilidades. Na sequência é apresentado os resultados obtidos nas análises, bem como as discussões. 


\section{RESULTADOS E DISCUSSÕES}

\subsection{Objetivos dos cursos}

Dos 36 PPP, os quais foi possível realizar a leitura, dez deles apresentavam na sessão de objetivos do curso indícios para uma formação na perspectiva inclusiva. Destacou-se que tais indícios puderam ser classificados como explícitos ou implícitos. Nos explícitos, considerou-se as menções diretas às temáticas da Educação Especial e/ou educação inclusiva e para os implícitos foram consideradas as inferências que levavam a interpretação de que tais temáticas poderiam ser abrangidas.

É apresentado no Quadro 2 os excertos obtidos das sessões de objetivos do curso nos PPP. Vale pontuar que são apresentados apenas os objetivos que, de alguma forma, apresentavam tendência a discutir a temática investigada. Dentre os documentos, os quais foi possível identificar os objetivos, notou-se que 13 cursos apresentou indícios explícitos vinculados à Educação Especial ou à educação inclusiva, conforme pode-se notar nos excertos destacados.

Quadro 2 - Excertos obtidos na sessão de objetivos nos PPP

\begin{tabular}{|c|c|}
\hline Indícios Explícitos & Indícios Implícitos \\
\hline $\begin{array}{l}\text { Forneça ao aluno conhecimentos }[. . .] \text { sobre } \\
\text { aprendizagem de alunos com necessidades especiais } \\
\text { (LM3, p. 12). }\end{array}$ & $\begin{array}{l}\text { Desenvolva um ensino que integre o saber da área } \\
\text { de conhecimento específico e o saber pedagógico } \\
\text { capaz de tornar o saber de Física acessível aos } \\
\text { alunos, articulando-o à realidade e às necessidades } \\
\text { da população estudantil (LF1, p. 9). }\end{array}$ \\
\hline $\begin{array}{l}\text { Orientar suas escolhas e decisões profissionais por } \\
\text { princípios éticos, pela superação de preconceitos, } \\
\text { pela aceitação da diversidade dos alunos, partindo } \\
\text { do princípio de que todo aluno é capaz de aprender. } \\
\text { (LQ4, p. 20; LM8, p. 2) }\end{array}$ & $\begin{array}{l}\text { Consciência da necessidade de se tornar agente } \\
\text { transformador da realidade presente, na busca da } \\
\text { melhoria da qualidade do ensino e de vida da } \\
\text { população como um todo (LQ3, p. 15). }\end{array}$ \\
\hline $\begin{array}{l}\text { Criar condições para que o licenciando possa } \\
\text { superar preconceitos pela aceitação da diversidade } \\
\text { dos alunos, partindo do princípio de que todo aluno } \\
\text { é capaz de aprender (LQ5, p. 15). }\end{array}$ & $\begin{array}{l}\text { Desenvolver atitude investigativa no aluno de } \\
\text { forma a abordar tanto problemas tradicionais } \\
\text { quanto problemas novos na sua área de atuação } \\
\text { partindo de princípios e leis fundamentais (LF11, } \\
\text { p. 36). }\end{array}$ \\
\hline \multirow[t]{2}{*}{$\begin{array}{l}\text { Promover a ampliação e o aperfeiçoamento do uso } \\
\text { da Língua Portuguesa e da capacidade } \\
\text { comunicativa, oral e escrita, como elementos } \\
\text { fundamentais da formação dos professores, e da } \\
\text { aprendizagem da Língua Brasileira de Sinais } \\
\text { (LIBRAS); (LF12, p. 10; LQ9, p.10). }\end{array}$} & $\begin{array}{l}\text { Analisar criticamente materiais didáticos de } \\
\text { Matemática (livros, softwares especializados etc.) } \\
\text { e elaborar propostas alternativas para a sala de } \\
\text { aula; (LM10, p. 38). }\end{array}$ \\
\hline & $\begin{array}{l}\text { Investigar sistematicamente progressos e } \\
\text { dificuldades dos alunos, e de sua própria prática, e }\end{array}$ \\
\hline
\end{tabular}


utilizar tal investigação como parte do processo de sua formação continuada. (LM10, p. 39);

Capacitar os futuros professores para lidar com questões socioambientais, éticas, estéticas e relativas à diversidade étnico racial, de gênero, sexual, religiosa, de faixa geracional, e sociocultural como princípios de equidade. (LF12, p. 10; LQ9, p.10).

Fonte: Elaboração própria.

Os excertos cuja inferência encontrou-se de forma implícita foram extraídos e considerados para essa análise, visto que eles remetiam indiretamente à temática da educação inclusiva. Vários pontos puderam ser elencados para corroborar com a constatação, como a preocupação de "tornar o saber de Física acessível aos alunos", o que vale para as demais disciplinas e remete a uma preocupação que a devida transposição didática dessa ciência seja realizada de modo a torná-la compreensível para todos os alunos, o que inclui os estudantes PAEE.

Pensar que cabe ao curso de licenciatura fornecer uma formação capaz de formar um profissional "na busca da melhoria da qualidade do ensino e de vida da população como um todo" (LQ3, p. 15), é vislumbrar uma formação adequada que capacite esse profissional a se preocupar e se responsabilizar com os fatores que comprometam o ensino, como a urgência em meios que garantam o pleno acesso ao currículo escolar para TODOS os alunos. Tal acesso pode ser alcançado quando se preocupa-se em "elaborar propostas alternativas para a sala de aula" (LM10, p. 38), uma vez que é de conhecimento que a escola é composta por uma diversidade enorme de estudantes, os quais, em grande parte, dependem de esforços do professor em busca de "Investigar sistematicamente progressos e dificuldades dos alunos" (LM10, p. 39). E, para o caso dessas dificuldades, surge a necessidade de estratégias que auxiliem o desenvolvimento dos alunos, considerando que "todo aluno é capaz de aprender" (LQ4, p. 20; LM8, p. 2), mesmo que seja por vias alternativas.

Os excertos destacados apontaram currículos cujos objetivos previam a formação de um professor preocupado com a diversidade apresentada pelos alunos, com a necessidade de transformar o conhecimento acessível, buscar propostas alternativas e objetivos que caracterizam uma formação preocupada com a investigação de dificuldades e progressos dos alunos, bem como meios para buscarem formar um 
profissional responsável pela melhora da qualidade de ensino. São sentenças que, mesmo que não tenham sido construídas intencionalmente, direcionaram a uma preocupação com uma educação inclusiva e que respeitasse as diferenças.

Complementar as Diretrizes Curriculares Nacionais para a Formação de Professores da Educação Básica, em nível superior, curso de licenciatura, de graduação plena, tem-se que a Resolução $n^{\circ} 2$, de $1^{\circ}$ de julho de 2015 , responsável por instituir as novas Diretrizes Curriculares Nacionais para a formação inicial em nível superior e para a formação continuada, apresenta a Educação Especial como um dos conteúdos específicos a serem garantidos nos currículos de cursos de formação de professores. E dentre os principais pontos em que a educação inclusiva é mencionada nesse documento, destacamos um dos preceitos da Formação de Profissionais do Magistério da Educação Básica, como sendo:

II - a formação dos profissionais do magistério (formadores e estudantes) como compromisso com projeto social, político e ético que contribua para a consolidação de uma nação soberana, democrática, justa, inclusiva e que promova a emancipação dos indivíduos e grupos sociais, atenta ao reconhecimento e à valorização da diversidade e, portanto, contrária a toda forma de discriminação (BRASIL, 2015, p. 4, grifos nosso).

Em seu artigo 8, as novas Diretrizes enumeram aptidões esperadas para os egressos de cursos de formação inicial, entre elas destacamos,

VIII - demonstrar consciência da diversidade, respeitando as diferenças de natureza ambiental-ecológica, étnico-racial, de gêneros, de faixas geracionais, de classes sociais, religiosas, de necessidades especiais, de diversidade sexual, entre outras (BRASIL, 2015, p. 8, grifos nosso).

Com base nesses trechos, pode-se traçar um perfil de um profissional egresso de um curso de licenciatura, o qual, de acordo com o documento, espera-se que seja formado para atuar de forma inclusiva, respeitando e valorizando a diversidade, assim como as diferenças de necessidades especiais de cada indivíduo.

\subsection{Componentes Curriculares e Competências e Habilidades}

Em termos curriculares, espera-se a presença da temática da Educação Especial nos currículos de cursos de licenciaturas por meio da oferta de disciplinas e adequações dos propósitos dos currículos. Uma das primeiras iniciativas nesse sentido foi a Portaria $\mathrm{n}^{\circ}$ 1793/94 (BRASIL, 1994), a qual presumia a necessidade de complementar os 
currículos de formação de professores pensando na Educação Especial. Diante disso, recomenda a inclusão da disciplina "Aspectos ético-político-educacionais da normalização e integração da pessoa portadora de necessidades especiais", prioritariamente, nos cursos de Pedagogia, Psicologia e em todas as Licenciaturas. No entanto, vale pontuar que tal portaria foi constituída sob influência das concepções defendidas na época as quais não convergem com a construção teórica e política estabelecida atualmente e, ainda, a literatura mostra que essa portaria não exerceu a influência esperada (CHACON, 2004). Atualmente e com resultados mais efetivos temse o decreto $\mathrm{n}^{\circ} 5626$ de 2005 que prevê a disciplina Língua Brasileira de Sinais (LIBRAS) como obrigatória em todas as licenciaturas. Dessa forma, essas disciplinas seriam esperadas para constituírem os currículos investigados.

A discussão da temática da Educação Especial é prevista nos currículos de cursos de licenciaturas, contemplados como elemento dos conteúdos referentes aos fundamentos da educação (BRASIL, 2015), conforme segue,

$\S 2^{\circ}$ Os cursos de formação deverão garantir nos currículos conteúdos
específicos da respectiva área de conhecimento ou interdisciplinares, seus
fundamentos e metodologias, bem como conteúdos relacionados aos
fundamentos da educação, formação na área de políticas públicas e gestão da
educação, seus fundamentos e metodologias, direitos humanos, diversidades
étnico-racial, de gênero, sexual, religiosa, de faixa geracional, Língua
Brasileira de Sinais (Libras), educação especial e direitos educacionais de
adolescentes e jovens em cumprimento de medidas socioeducativas
(BRASIL, 2015, p. 11).

As análises das Matrizes Curriculares possibilitaram identificar uma quantidade de 76 disciplinas distribuídas nas licenciaturas investigadas, a maioria dos cursos oferta ao menos uma disciplina cujos tópicos da Educação Especial e/ou Educação Inclusiva se faz presente.

Os PPP que não apresentaram detalhamento de ementa ou essa encontrava-se muito limitada, dificultou a identificação de tópicos de Educação Especial, caso estivessem presentes, uma vez que identificamos que algumas disciplinas, embora não carregassem explicitamente no nome essa temática, no detalhamento da ementa foi possível identificar conteúdos relacionados à questão. 
Quanto ao ano de atualização dos PPP, todos os que possuíam essa informação disponível tinham sido atualizados após as diretrizes para formação de professores da educação básica (BRASIL, 2002). Verificou-se a presença da disciplina referente à LIBRAS, presente em $42 \%$ do total de disciplinas ofertadas e disponíveis nas matrizes curriculares das licenciaturas analisadas. Assim, considerando o decreto $\mathrm{n}^{\circ} 5626$ de 2005 que regulamenta a inclusão da disciplina de LIBRAS em cursos de licenciaturas (BRASIL, 2005a), pode-se dizer que houve impacto nas grades dos cursos. Nas análises foi possível identificar os cursos que foram reformulados após a publicação desse decreto, embora ainda não se mostraram adequados para atender a essa exigência, mas, por outro lado, o curso LF8, cujo PPP foi reformulado em 2004, já contemplava a disciplina de LIBRAS.

Notou-se a presença de três disciplinas com perfil de instrumentação do ensino específico com a Educação Especial, como no curso LQ1 a disciplina denominada de "Elaboração de Material Didático para o ensino de Química e Ciências", a qual traz em seu conteúdo programático e ementa, respectivamente:

Material didático inclusivo e a didática multissensorial: elaboração de material didático para portadores de necessidades educacionais especiais. (LQ1, p. 183)

Busca-se também ao estudo dos referenciais teóricos de base, a elaboração e adaptação de materiais didáticos para o Ensino de Química e ciências para pessoas com necessidades educacionais especiais e para educação de jovens e adultos (LQ1, p. 186).

Ou seja, embora notou-se o uso de nomenclaturas desatualizadas, percebeu-se que a disciplina se propunha a discutir as possibilidades do ensino da química com a Educação Especial. Entende-se que abordar tal temática vinculada ao conhecimento específico de formação pode tornar o professor muito mais capacitado para lidar com o ensino para o estudante PAEE. Nesse contexto, concordamos com Theobald (2006) quando enfatiza a importância de

primar pela formação de egressos que além de dominar competências específicas do campo de saber da Matemática (o que vale para todas as licenciaturas) agreguem à sua formação profissional as competências do "ensinar bem" o conhecimento Matemático àqueles que lhe forem confiados como alunos pela vida afora (THEOBALD, 2006, p. 6, destaque nosso). 
Cabe mencionar que os trabalhos desenvolvidos e apresentados na literatura nacional, os quais contemplam exemplos para práticas com foco, em específico, no ensino de ciências para estudantes PAEE (ver CAMARGO, 2007; BASSO, 2012, entre outros).

São estudos que apresentam estratégias diversificadas, muitas vezes acessíveis, e com materiais de fácil acesso. Assim, pode-se considerar que a comunidade científica tem cumprido seu papel no desenvolvimento de novos conhecimentos frente à problemática da inclusão de estudantes PAEE no ensino regular. Porém, para o escopo de nossas investigações, notou-se ainda um distanciamento entre os currículos analisados e os novos conhecimentos abordados na literatura. Verificou-se ainda a prevalência de disciplinas ofertadas apenas por recomendações legais, sem que houvesse a devida reflexão acerca das capacidades humanas individuais (PLETSCH, 2009), o que, de acordo com Bueno (1999), pode resultar em práticas contrárias aos princípios da educação inclusiva.

A sessão de competências e habilidades foi também analisada nos PPP, considerando que foram elencadas e previstas competências na formação de professores da educação básica (BRASIL, 2002). Dos PPP analisados, onze apresentavam seções nas quais eram descritas as competências e habilidades para os egressos, conforme segue:

Reconhecer e respeitar a diversidade manifestada por seus alunos, em seus aspectos sociais, culturais e físicos, detectando e combatendo todas as formas de discriminação (LM9, p. 7; LQ3, p. 27).

Reconhecer e respeitar a diversidade manifestada por seus alunos, em seus aspectos sociais, culturais e físicos, detectando e combatendo todas as formas de discriminação (LM3, p.13).

Manejar diferentes estratégias de comunicação dos conteúdos, sabendo eleger as mais adequadas, considerando a diversidade dos alunos, os objetivos das atividades propostas e as características dos próprios conteúdos (LQ3, p. 29; LM10, p. 45).

Utilizar estratégias diversificadas de avaliação da aprendizagem e, a partir de seus resultados, formular propostas de intervenção pedagógica, considerando o desenvolvimento de diferentes capacidades dos alunos (LQ3, p. 29; LM10, p. 45). 
Domínio dos princípios gerais e fundamentais da Física, metodologias e práticas didáticas com objetivo de conhecer e se preparar para a diversidade de situações de aprendizagem e de ensino (LF2, p. 10).

A elaboração ou adaptação de materiais didáticos de diferentes naturezas, identificando seus objetivos formativos, de aprendizagem e educacionais (LF4, p. 6).

Um futuro professor capaz de compreender a diversidade de situações, informações e tecnologia presentes no cotidiano daqueles que frequentam a escola (LF5, p. 10).

Desenvolver metodologias e materiais didáticos de diferentes naturezas, coerentemente com os objetivos educacionais almejados (LF8, p. 8).

Analisando as competências e habilidades previstas, notou-se que estavam de acordo com as previstas pelas Diretrizes Curriculares Nacionais para a Formação de Professores de Educação Básica. No entanto, embora os cursos, em sua maioria, tenham sido atualizados após a publicação dessas diretrizes, verificou-se que ainda não estão totalmente adequados. Vale pontuar que mesmo que não sejam diretamente direcionados à Educação Especial ou Educação Inclusiva, tais excertos trouxeram indícios indiretos a essas temáticas, como quando é mencionada a questão do respeito à diversidade, ao uso de estratégias diversificadas no intuito de oferecer oportunidades diferenciadas as diferentes especificidades apresentadas pelos estudantes e ainda podese destacar a habilidade de lidar com a necessidade de desenvolvimento de materiais didáticos de diferentes naturezas, estratégia válida que pode garantir mais oportunidades de aprendizagem.

\section{CONSIDERAÇÕES FINAIS}

O foco desse estudo foi o de verificar a presença/ausência de tópicos relacionados à Educação Especial e/ou à educação inclusiva nos cursos de licenciaturas em ciências exatas ofertados em universidades públicas de um estado brasileiro. A fonte de dados foram os PPP de cada curso, assim como suas respectivas MC. Foram analisados um total de 36 cursos de licenciaturas, entre as quais encontraram-se: Licenciatura em Física, Licenciatura em Química, Licenciatura em Matemática e Licenciatura em ciências exatas (que se refere às três ciências).

Considerando que são os PPP dos cursos que elencam as pretensões do profissional que será formado ao término da licenciatura, apoiados nos dados que 
emergiram nas análises referente a esse estudo, pode-se manter as preocupações com respeito ao processo de inclusão escolar nas escolas regulares. São duas as vias que preocupam, sendo de um lado estudantes PAEE que apresentam dificuldades de acesso em aulas de física, química e matemática; e de outro lado, professores das referidas disciplinas que não saberão lidar com as dificuldades, visto que os currículos evidenciam uma precária (ou ausente) formação para lidar com esse público.

Pensar que a inclusão escolar de estudantes PAEE vai muito além de apenas garantir sua matrícula em salas de aula regulares. É necessário garantir sua permanência e sucesso nesse espaço e, para isso, há de se considerar a adequada formação de professores do ensino regular, assim como de professores de Educação Especial como de suma importância (GIROTO; POKER; OMOTE, 2012).

O estudo aqui apresentado pode reforçar o clichê de que "os professores do ensino regular não estão preparados para lidar com a heterogeneidade da sala de aula" (MENDES, 2012). No entanto, adicionalmente ao apontamento de fatos já elencados por outros autores e lacunas, é importante propor estratégias para contribuir com tais problemas, visto que um dos propósitos da ciência é a produção de novos conhecimentos (MENDES, 2008).

Em respeito à literatura científica, ao convergir para a formação docente no âmbito das ciências exatas ou naturais, notou-se a presença das mesmas problemáticas destacadas para as licenciaturas no geral. Professores de ciências despreparados para lidarem com estudantes PAEE (THEOBALD, 2006; VILELA-RIBEIRO; BENITE, 2010), currículos cujo conhecimento acerca da Educação Especial não é abordado ou insuficiente (VILELA-RIBEIRO; BENITE, 2011; OLIVEIRA et al., 2011; LIMA; CASTRO, 2012; BASSO, 2015; PEDROSO; CAMPOS; DUARTE, 2013). Logo, essa é uma problemática enfrentada por todas as licenciaturas em geral e também pelas licenciaturas da área de ciências exatas.

Dessa forma, apenas a recomendação de inserir conteúdos, disciplinas ou para se mudar grades curriculares de cursos de ensino superior tem se mostrado, ao longo do tempo, como medida inócua, uma vez que a composição de currículos tem sido arenas políticas, nas quais várias propostas de formação e reformulação de cursos confrontam- 
se. A exigência de inclusão de conteúdos por decreto, por outro lado, como foi o caso da disciplina de LIBRAS, parece ter sido uma medida mais efetiva para garantir a presença de certos conteúdos nos cursos de formação de professores, embora não seja garantido que de fato tal inserção ocorrerá, dado que alguns cursos ainda não atendem as exigências legais.

O fato é que anualmente nossas universidades formam professores que muitas vezes desconhecem o fato de que terão seguramente alunos do PAEE em suas turmas. Esses professores que desconhecem as leis e os direitos desses estudantes poderão continuar questionando a presença dos alunos PAEE na escola ou inviabilizando que eles tenham acesso ao currículo. Eles continuaram reclamando, e com razão, pois não foram preparados para ensinarem tais alunos e não poderão contribuir para a construção de uma escola mais inclusiva, mais justa e menos desigual.

Assim, observou-se que a despeito das intenções da política educacional de seguir os pressupostos da inclusão escolar, há contraditoriamente um problema que evidenciou a falta de vontade política de melhorar a formação de professores para que esse fim seja atingido.

Em paralelo às mudanças necessárias na política de formação de professores, observou-se, por outro lado, no campo da investigação científica, a necessidade de ir além das propostas tradicionais de formação de professores da educação geral, no campo da educação inclusiva, para se investigar formatos mais inovadoras e que sejam capazes de atrair esses jovens estudantes e futuros professores para essa temática.

\section{REFERÊNCIAS}

BASSO, S. P. S.; GIMENO, J. G.; CAMARGO, E. P.; DASCANIO, D.; ANJOS, P. T. A.; ALMEIDA, T. J. B. Material didático multissensorial: a fecundação para deficientes visuais. Revista da SBEnBIO, v. 1, p. 1-8, 2012.

BASSO, S. P. S. Cursos de licenciatura na área de ciências: a temática inclusão escolar de alunos com necessidades educacionais especiais. 2015. $130 \mathrm{f}$. Tese (Doutorado em Educação para a Ciência) - Universidade Estadual Paulista Júlio de Mesquita Filho, Faculdade de Ciências, 2015.

BRASIL. Constituição da República Federativa do Brasil. Brasília: Senado Federal, 1988. Disponível em:

http://www.planalto.gov.br/ccivil_03/Constituicao/Constituicao.htm. Acesso em: 07/02/2018. 
Ministério da Educação e do Desporto. Portaria 1793, de dezembro de 1994. Recomenda a inclusão da disciplina ou conteúdos sobre aspectos ético-político pedagógico educacionais da normalização e integração da pessoa portadora de necessidades especiais em cursos de graduação. 1994. Disponível em: http://portal.mec.gov.br/arquivos/pdf/portaria1793.pdf. Acesso em: 16/08/2018.

Lei 9.394, de 20 de dezembro de 1996. Estabelece as diretrizes e bases da educação nacional. Disponível em: http://www.planalto.gov.br/ccivil_03/LEIS/L9394.htm. Acesso em: 13/07/2018.

Ministério da Educação - MEC. Secretaria de Educação Fundamental - SEF. Referências para a Formação de Professores. Brasília: 1999. Disponível em: https://www.novaconcursos.com.br/blog/pdf/referencias-formacao-professores.pdf. Acesso em: 13/07/2018.

Ministério da Educação. Proposta de Diretrizes para a formação de professores da Educação Básica, em curso de nível superior: versão preliminar. Maio de 2000. Brasília, 2000. Disponível em: http://portal.mec.gov.br/cne/arquivos/pdf/prof050301.pdf. Acesso em: 13/07/2018.

Parecer CNE/CP 9/2001. Diretrizes Curriculares Nacionais para a

Formação de Professores da Educação Básica. Nível Superior, curso de licenciatura, de graduação plena. Brasília: MEC, 2002. Disponível em: http://portal.mec.gov.br/cne/arquivos/pdf/009.pdf. Acesso em: 13/07/2018.

Parecer CNE/CES 1.304/2001. Diretrizes Curriculares Nacionais para os cursos de Física. Brasília: MEC, 2001a. Disponível em: http://portal.mec.gov.br/cne/arquivos/pdf/CES1304.pdf. Acesso em: 22/03/2018.

Parecer CNE/CES 1.303/2001. Diretrizes Curriculares Nacionais para os cursos de Química. Brasília: MEC, 2001b. Disponível em: http://portal.mec.gov.br/cne/arquivos/pdf/CES1303.pdf. Acesso em: 22/03/2018.

Parecer CNE/CES 1.302/2001. Diretrizes Curriculares Nacionais para os cursos de Matemática. Brasília: MEC, 2001c. Disponível em: http://portal.mec.gov.br/cne/arquivos/pdf/CES13022.pdf. Acesso em: 22/03/2018.

Decreto $^{\circ} 5626$ de 2005. Regulamenta a Lei $n^{\circ} 10.046$, de 24 de abril de 2002, que dispõe sobre a Língua Brasileira de Sinais - Libras - e o art. 18 da Lei $\mathrm{n}^{\circ}$ 10.098, de dezembro de 2000. Brasília: Casa Civil, 2005. Disponível em: http://www.planalto.gov.br/ccivil_03/_ato2004-2006/2005/decreto/d5626.htm. Acesso em: 22/03/2018.

Resolução no 2, de $1^{\mathbf{0}}$ de julho de 2015. Define as Diretrizes Curriculares Nacionais para a formação inicial em nível superior (cursos de licenciatura, cursos de formação pedagógica para graduados e cursos de segunda licenciatura) e para a formação continuada. 2015. Disponível em: http://portal.mec.gov.br/docman/agosto2017-pdf/70431-res-cne-cp-002-03072015-pdf/file. Acesso em: 16/08/2018.

Decreto $\mathbf{n}^{0} 8.752$ de 2016. Dispõe sobre a Política Nacional de Formação dos Profissionais da Educação Básica, 2016. Disponível em: 
http://www.planalto.gov.br/ccivil_03/_Ato2015-2018/2016/Decreto/D8752.htm. Acesso em: 18/07/2018.

BRUNO, M. M. G. Educação Inclusiva: Componente da Formação de Educadores. Revista Benjamin Constant, ano 13, n. 38, 2007.

BUENO, J. G. Crianças com necessidades educativas especiais, política educacional e a formação de professores: generalistas ou especialistas. Revista Brasileira de Educação Especial, v. 3. n. 5, p. 7-25, 1999.

CAMARGO, E. P. É possível ensinar física para alunos cegos ou com pouca visão? Proposta de atividades de ensino de física que enfocam o conceito de aceleração. Física na Escola, v. 8, n. 1, p. 30 - 34, mai. 2007.

CHACON, M. C. M. Formação de Recursos Humanos em Educação Especial: resposta das Universidades à recomendação da portaria ministerial $n^{\circ}$ 1.793. Revista Brasileira de Educação Especial, v.10, n. 3, p. 321-336, 2004.

GIROTO, C. R. M.; POKER, R. B.; OMOTE, S. As tecnologias nas práticas pedagógicas inclusivas. Marília. Oficina Universitária. São Paulo: cultura Acadêmica, 2012.

GLAT, R. Capacitação de professores: pré-requisito para uma escola aberta à diversidade. Revista Souza Marques, v.1, p. 16-23, 2000.

LIMA, M. C. B.; CASTRO, G. F. Formação inicial de professores de física: a questão da inclusão de alunos com deficiências visuais no ensino regular. Ciência \& Educação, v. 18, n. 1, p.81-98, 2012.

MENDES, E. G. Pesquisas sobre inclusão escolar: revisão da agenda de um grupo de pesquisas. Revista Eletrônica de Educação, v. 2, n.1, p.3-25, 2008.

MENDES, E. G.; CIA, F.; CABRAL, L. S. A. (Orgs.). Inclusão Escolar e os Desafios para a Formação de Professores em Educação Especial. 1. ed. São Carlos: Marquezine \& Manzine, 2015. v. 3. 530p.

MENDES, E. Prefácio. In: GLAT, R; PLETSCH, M. D. Inclusão escolar de alunos com necessidades especiais [online]. 2 ed. 164 p. Rio de Janeiro: EdUERJ, 2012.

MESQUITA, N. A. S.; SOARES, M. H. F. B. Relações entre Concepções

Epistemológicas e Perfil Profissional Presentes em Projetos Pedagógicos de Cursos de Licenciatura em Química do Estado de Goiás. Química nova escola, v. 31, n. 2, 2009.

OLIVEIRA, M. L; ANTUNES, A. M.; ROCHA, T. L.; TEIXEIRA, S. M. Educação Inclusiva e a formação de professores de Ciências: o papel das universidades federais na capacitação dos futuros educadores. Revista Ensaio, v. 13, n. 3, p. 99-117, 2011.

PEDROSO, C. C. A.; CAMPOS, J. A. P. P.; DUARTE, M. Formação de professores e educação inclusiva: análise das matrizes curriculares dos cursos de licenciatura.

Educação Unisinos, v. 17, n. 1, 2013. 
PLETSCH, D. A formação de professores para a educação inclusiva: legislação, diretrizes políticas e resultados de pesquisas. Educar em revista, n. 33, p. 143-156, 2009.

THEOBALD, I. M. Docência e diversidade nas licenciaturas: reflexões de futuros docentes em matemática e física. Revista Iberoamericana de Educación. n. 40, p. 1-6, 2006.

UNESCO. Conferência Mundial de educação para todos, Jomtien. Declaração mundial sobre educação para todos: satisfação das necessidades básicas de aprendizagem. Jomtien: Unesco, 1990.

UNESCO. Declaración de Salamanca de principios, política y práctica para las necesidades educativas especiales. 1994.

VILELA-RIBEIRO, E. B.; BENITE, A. M. C. A Educação Inclusiva na percepção dos professores de Química. Ciência \& Educação, v. 16, n. 3, p.585-594, 2010.

VILELA-RIBEIRO, E. B.; BENITE, A. M. C. Sobre a educação inclusiva na formação de professores de Ciências: a tessitura dos currículos praticados. Acta Scientiarum, v. 33, n. 2, p. 239-245, 2011. 